\title{
De Salas Murillo, Sofía (Coord.) (2013) Los mecanismos de guarda legal de las personas con discapacidad tras la Convención de Naciones Unidas. Madrid: Editorial Dykinson, Colección Monografías de De- recho Civil, Persona y Familia, 284 pp.
}

La obra en comento se compone de doce colaboraciones elaboradas por destacadas personalidades del ámbito europeo, entre las que figuran profesores y catedráticos de derecho civil y derecho procesal civil de diferentes universidades españolas, tales como Carlos Martínez de Aguirre y Aldaz, Gabriel García Cantero, María Victoria Mayor del Hoyo, Regina Gacimartín Montero, Antonio Legerén Molina y Ángeles Parra Lucán; participan también en ella el Canciller de la Corte de Casación francesa, Francois Monéger; la destacada profesora Elvira Gabriella Autorino, de la Universidad de Salermo, el profesor alemán Rainer Frank; Marta Chimeno Cano, Magistrada Titula del Juzgado de Primera Instancia, N. 7 de Tarragona; Jaime Sanaú Villaroya, Presidente de la Fundación Tutelar Luis de Azúa y profesor titular de economía aplicada; María Frontera Sancho y Carlos Gómez Bahíllo, profesores de psicología evolutiva y sociología, respectivamente; José Carlos Fuertes Rocañin, médico forense y especialista en psiquiatría; y María Jesús Germán Urdiola, Doctora en Derecho, todos los cuales abordan la temática de la discapacidad desde la óptica de sus especialidades, presentando al lector el material más completo y multidisciplinario que se haya publicado hasta hoy, tanto a nivel europeo como a nivel mundial.

La serie de estudios es coordinada por Sofía de Salas Murillo, profesora titular de Derecho civil de la Facultad de Derecho de la Universidad de Zaragoza, especialista en Derecho de familia y de la persona y con abundante producción doctrinal en la materia.

En el año 2013 se cumplen en España 30 años de vigencia de la ley 13/1983, de 24 de octubre, a través de la cual se reformó el Código Civil español en materia de tutela. Vigente tal legislación, que solo fue modificada en algunos aspectos a través de la ley de Enjuiciamiento Civil del año 2000, surge la aprobación, en el año 2006 de la Convención de $\mathrm{Na}$ ciones Unidas de los Derechos de Personas con Discapacidad, ratificada por España en noviembre del año 2007 y publicada en el Boletín Oficial del Estado en del año 2008. Desde entonces, la Ley 26/2011 ha modificado una serie de normas del ordenamiento jurídico espańol con el objeto de adaptar las disposiciones al instrumento internacional, sin abordar hasta ahora los aspectos jurídico privados que le subyacen. Es en este contexto que la obra colectiva que en estas líneas se presenta aparece como un aporte doctrinal fundamental a dicha tarea pendiente.

El volumen presentado se divide en tres apartados. El primero de ellos se titula "El sistema de guarda legal de las personas con discapacidad: 
¿reforma o ruptura?”. En él se aborda el impacto de la Convención tanto en el sistema jurídico español, como en el entorno europeo, haciéndose hincapié en la intensa disyuntiva docrinal y judicial entre romper con el sistema de tutela de autoridad y de capacidad jurídica y capacidad de obrar, o reformarlo sobre la base del sistema ya existente. Destacan entre los cinco artículos que componen la primera parte del libro, los estudios dedicados al tratamiento de la discapacidad y la solución dada por los ordenamientos jurídicos y la doctrina de Francia, Italia y Alemania. En el primero de ellos, Francois Monéger, bajo el título "La protection juridique des personnes après la ratificación par la France de la Convention des Nations Unies relative aux droits des personnes handicapeés", aborda el respeto a la personalidad jurídica de la persona y su protección extrapatrimonial; la importancia primordial de la familia y su prioridad de protección, mencionada tanto en el apartado X del preámbulo de la Convención, como en el artículo 499 del Código Civil francés, y el acceso una justicia acorde al instrumento internacional. Enseguida, Elvira Gabriella Autorino, expone las soluciones dadas por el ordenamiento jurídico italiano en torno a la incapacidad, centrándose principalmente en la funcionalidad de la protección y la justificación de diferentes procedimientos y normas procesales que marcan su contenido, así como en la premisa de que la prestación de apoyo administrativo debe ser estructurada a través de la indicación de ciertas operaciones de apoyo en nombre del administrado, mientras que para todos lo demás el beneficiario debe conservar la capacidad de actuar y puede llevar a cabo los actos necesarios para satisfacer las necesidades de su vida cotidiana. Por último, aunque escrito en idioma francés, el alemán Rainer Frank presenta el tratamiento de las discapacidades mentales en Alemania, poniendo especial énfasis en la situación jurídica de los mismos antes de la reforma de 1992, y la existente desde entonces hasta nuestros días. A partir de alí, se centra el autor en la protección de los mayores de edad; en la figura de reserva del consentimiento; y en el derecho de autodeterminación de las personas sometidas a un régimen de protección; la privación de libertad por intermedio de un mandatario; la necesidad y obligación de cuidados médicos; y, por último, realiza una breve referencia relativa al matrimonio y a la facultad de testar de los discapacitados.

El segundo apartado, titulado "Tutela y curatela: problemas de funcionamiento", se basa en el funcionamiento efectivo de tutela y curatela, con sus defectos y virtudes. Las investigaciones presentadas en este segmento, emanan no solo de académicos del Derecho civil, sino también de profesionales que prestan un enfoque procesal, judicial, institucional, sociológico y de psicología evolutiva de las figuras de tutela y curatela en el sistema nacional español. De entre los trabajos presentados, destaca el estudio realizado por Regina Gacimartín, orientado a la exposición del 
procedimiento español de designación judicial de guardador legal, y el trabajo de Antonio Legerén Molina, quien explica el funcionamiento de la guarda legal ejercida por personas jurídicas en el ordenamiento jurídico español. En el primero de ellos, la autora dedica sus páginas al análisis de la intervención del juez en el nombramiento de tutor y su estrecha relación con el pronunciamiento de incapacitación, como a los trámites procesales aptos para la designación de guardador, entre los que destacan el proceso de incapacitación, el expediente de jurisdicción voluntaria y la exposición de los parámetros para la adopción de la decisión judicial en materia de guarda legal (criterios legales y actividad probatoria).

En el tercer y último apartado, bajo el epígrafe "Otras figuras de guarda y protección de las personas con discapacidad", se vislumbra la existencia de instituciones jurídicas distintas a la tutela, curatela y defensor judicial, que están llamadas a apoyar a las personas con discapacidad según lo señalado en el art. 12. 3 de la Convención de las Naciones Unidas sobre los Derechos de las Personas con Discapacidad, en los siguientes términos: "Los Estados Partes adoptarán las medidas pertinentes para proporcionar acceso a las personas con discapacidad al apoyo que puedan necesitar en el ejercicio de su capacidad juridical". Destacamos en este apartado final, el trabajo de María Ángeles Parra Lucán, quien en uno de los estudios más extensos que presenta la obra, aborda la temática de la guarda de hecho de las personas con discapacidad, como aquella que ejerce quien no tiene ningún nombramiento tutelar ni ningún deber respecto de un menor o de una persona discapacitada, abarcando las tendencias de las distintas comunidades autónomas en la materia. También destaca el trabajo de autoría de José Carlos Fuertes Rocañín, especialista en psiquiatría, quien dedica sus líneas a profundizar en las patologías ambulatorias y la evolución legal del tratamiento involuntario, como gran asignatura pendiente que presenta no pocos problemas asistenciales, tanto para los propios enfermos, como para sus familiares y para los médicos que les asisten, problemática que tiene su origen en las peculiaridades de la enfermedad mental, como la ausencia de conciencia y las severas dificultades para objetivar mediante pruebas de exploración complementarias, entre otras. A su vez, el doctor Fuertes se refiere a las propuestas de modificación del artículo 763 de la Ley de Enjuiciamiento Civil y al Proyecto de Ley de jurisdicción voluntaria de 20 de octubre de 2006 que no alcanzó a ver la luz.

Sin duda, se recomienda la lectura de la obra aquí presentada, no solo por su carácter multidisciplinario en el tratamiento del régimen jurídico de la discapacidad a nivel europeo y de la Convención de la $\mathrm{Na}$ ciones Unidas sobre Derechos de Personas con Discapacidad, sino porque significa un aporte doctrinal incalculable que permitirá adecuar los ordenamientos jurídicos al tratado internacional, de manera de cumplir cabalmente con lo dispuesto por la norma. Asimismo, el trabajo se presenta 
como bibliografía indispensable para aquellos investigadores de nuestro país que se inician en la temática jurídica de la discapacidad.

\section{DANiela Jarufe ConTreras*}

* Profesora de Derecho Civil de la Facultad de Ciencias Jurídicas de la Universidad Católica del Norte (ChIle). Magíster en Investigación Jurídica; Doctora en Derecho por la Universidad de Zaragoza (España). Correo electrónico: djarufe@ucn.cl 